\title{
Metals in the circular economy
}

\author{
Vessela Petrova ${ }^{1 *}$ \\ ${ }^{1}$ University of Mining and Geology "St. Ivan Rilski”, Economy and Management Department, 1700 \\ Sofia, Bulgaria
}

\begin{abstract}
Traditionally, green technologies are associated with renewable materials, such as wood, biomass, water and earth, instead of the metals that formed the backbone of the industrial revolution - steel, copper, iron, tin and aluminum. Although at first glance it does not seem that they will play a role in the sustainable transition, in fact many of the building blocks of the circular economy would not exist without them [1]

A number of European organizations are adamant that non-ferrous metals are essential for Europe's low-carbon transition because of their central use in breakthrough technologies including clean mobility, renewable energy and batteries. Moreover, they play a significant role in the circular economy strategy launched by the European Commission in 2015.

Contrary to this assertion, another one claims that the circular economy should be linked to reduced material use and waste consumption.
\end{abstract}

\section{Introduction}

The global use of minerals has been growing exponentially for a long time now. Growth rates vary but the U.S. Geological Survey (USGS) statistics show annual averages of about $3 \%$ for more than a century. The question is whether the Earth will be able to sustain similar growth in the future. In this regard, there are repeated expressions of concern about the future availability of resources. [2]

According to the linear economy model, raw materials are used to produce products that are disposed as waste after consumption. This concept is clearly defined as unsustainable over time and that requires the implementation of a new economic system, defined as a circular one, according to which one of the main goals of every person and company should be to mitigate the negative impact on the environment. The prudent use of raw materials can also have a beneficial effect on combating of the climate change, as the extraction and consumption of raw materials increases energy consumption and greenhouse gas emissions. Today, the concept of a circular economy is entering the regulatory framework and life in Europe at an increasingly aggressive pace. This need is caused by the shocking statistics that the European Union produces over 2.5 billion tons of waste a year. [3]

In essence, the circular economy is a model aimed at extending the life cycle of products. When a product reaches the end of its life the materials it is composed of continue to be used in another way. This repeats again and again, and thus minimizing the waste disposal.

\footnotetext{
*Corresponding author: vessela.petrova@mgu.bg
} 


\section{Significance of raw materials for European economy}

The raw materials are crucial for the European Union and the European economy and they are at the heart of our sustainable future. They form a strong industrial base and are at the core of everyone's daily life due to their key role in a wide range of products, applications and technologies. However, they are also at the heart of the low-carbon and circular economy. It is impossible to build power plants for wind and solar energy, as well as electric vehicles, without significant amounts of copper, aluminum, steel. Therefore, the limited raw materials and energy resources the demand for which inevitably grows determine the need for circular processes. Often their amount within the EU is not sufficient and European countries become dependent on imports from other countries. K. Lee and J. Cha [4] identify antimony, baryte, bauxite, beryllium, bismuth borate, cobalt, coking coal, fluorspar, gallium, germanium, hafnium, heavy rare earth elements, indium, light rare earth elements, lithium, magnesium, natural graphite, natural rubber, niobium, platinum group metals, phosphate rock, phosphorus, scandium, strontium, silicon metal, tantalum, titanium, tungsten, vanadium.

It is entirely expected that the transition to a circular economy and clean energy is achieved through the use of a number of natural resources. It is therefore very important to determine the extent to which the demand for mineral resources will grow worldwide to supply the resources needed for the circular processes. Table 1 tracks the minerals with the greatest weight and importance for each identified technology - copper, aluminum, molybdenum, cobalt and nickel. All these elements are needed for a number of low-carbon technologies that will help achieve the low-carbon future. The list is by no means exhaustive but it does review some of the most important minerals for the circular economy that are the subject of this publication.

Table 1. Mapping minerals with Relevant Low-Carbon Technologies, Adapted from Minerals for Climate Action: The Mineral Intensity of the Clean Energy Transitions, 2020

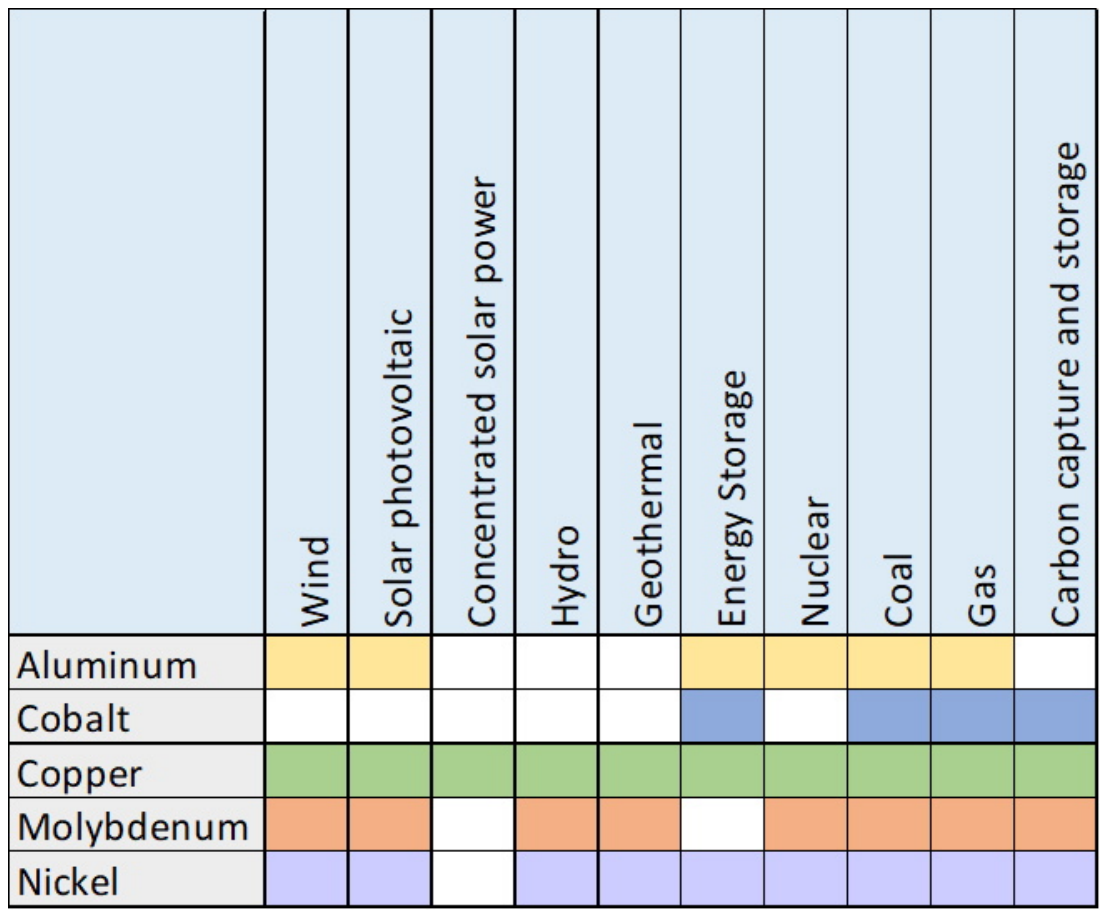


Copper is one of the most suitable examples of a natural resource, which is the basis of many global trends and has long been known as a circular material in the mineral industry. The life of copper is virtually endless and has no final phase. Once extracted, it can be recycled repeatedly without losing its properties. Moreover, copper is at the heart of several areas of growth including clean energy, mobility and energy efficiency. As a sustainable material, copper is the key to building a circular economy.

A combined growth rate of material demand of $4.1 \%$ per year is forecast reaching an annual figure of 9.7 million tons of demand by 2035. Wind and solar energy are currently $12 \%$ from the global energy mix and each is expected to make up more than one terawatt of the global capacity by 2035 . Electric vehicles, which could form about $34 \%$ of global sales by 2035 , contain more copper than conventional vehicles due to additional wiring, electric motors and batteries. [7]

According to the Fraunhofer Institute, approximately 440 million tons of copper were used worldwide in 2015. Almost 27 million tons of material were put into operation in 2015 including 8.5 million tons of recycled copper. [8]

The recycling on its own account cannot meet the growing demand for copper; however, the contribution of recycling to the global supplies can be increased through improved collection and investments in the development and use of improved technologies for separation of defective products. In this context, the statistics according to which with the advent of circular processes and low-carbon technologies, copper extraction reaches its peak are completely logical. Respectively, the price of copper is increasing as a stable trend. Fig. 1 marks the steady rate at which it rises.

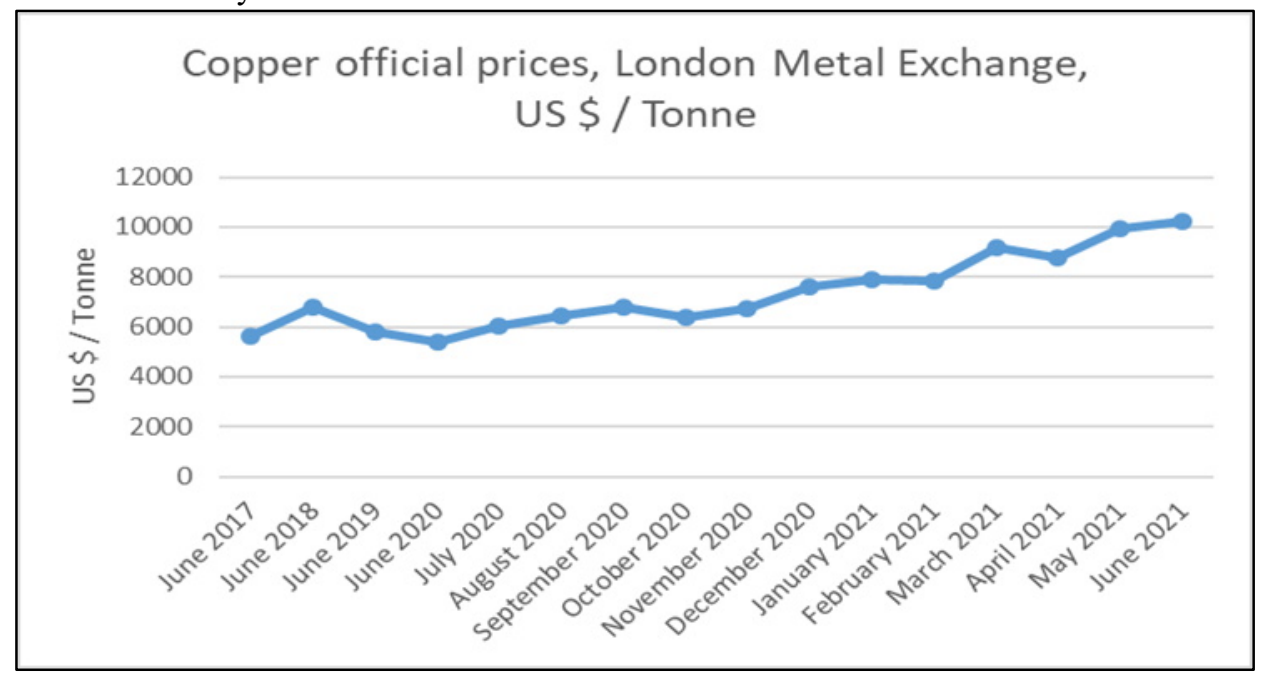

Fig. 1. Prices of copper based on the London Metal Exchange for the period 2017-2021

Aluminum is also recognizable as an all-circular metal. Being endlessly and $100 \%$ recyclable, it can be transformed by using it again in the production cycle.

The aluminum waste from production is recycled to obtain new raw material by recycling and melting. Furthermore, the aluminum does not lose its quality after recycling. Thus, the recycled aluminum does not differ from the one obtained from the original mineral (bauxite) and its main characteristics remain unchanged.

However, recycling the aluminum saves $95 \%$ of the energy needed to produce it starting with the mineral. In particular, $16 \mathrm{~kW} / \mathrm{h}$ are needed to produce $1 \mathrm{~kg}$ of bauxite aluminum while $0.4 \mathrm{~kW} / \mathrm{h}$ is needed to produce $1 \mathrm{~kg}$ of new aluminum from waste. [9]

Based on the London Metal Exchange, the prices per ton of aluminum are fully justified and tracking them in retrospect marks a smooth and steady rise (Fig. 2). This situation could 
also be determined by the entry of the European Green Park and the forthcoming Climate Act, which has been based exactly on the circular processes.

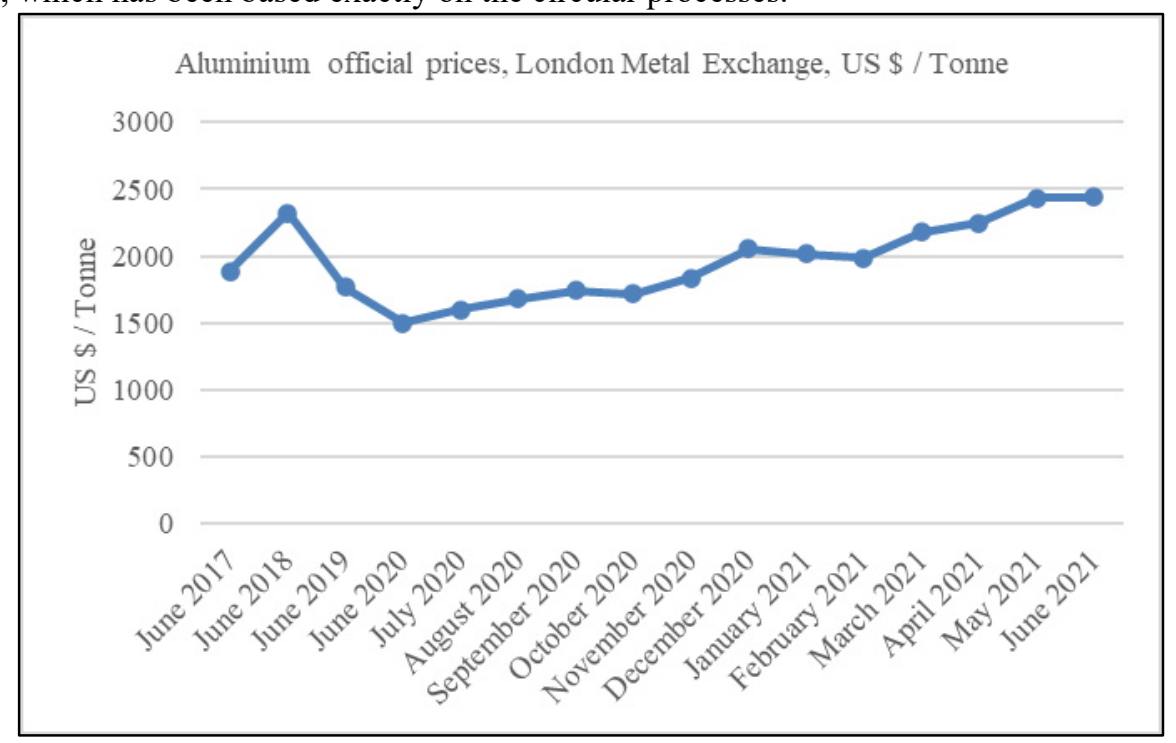

Fig. 2. Prices of aluminium based on the London Metal exchange for the period 2017-2021

According to Kleijn et al. [10], molybdenum is among the most important minerals needed to generate clean energy. This is the reason marking of permanent molybdenum reserves is very important for both society and future generations. In 1950, world production of molybdenum was 14,500 tons and in 2015 it reached 235,000 tons. This is equivalent to sixteen times growth over a period of 65 years or an annual growth rate of $4.4 \%$. [11] This high growth rate is unlikely to last forever. Fig. 3 unequivocally marks the gradual price rise of molybdenum according to the London Metal Exchange.

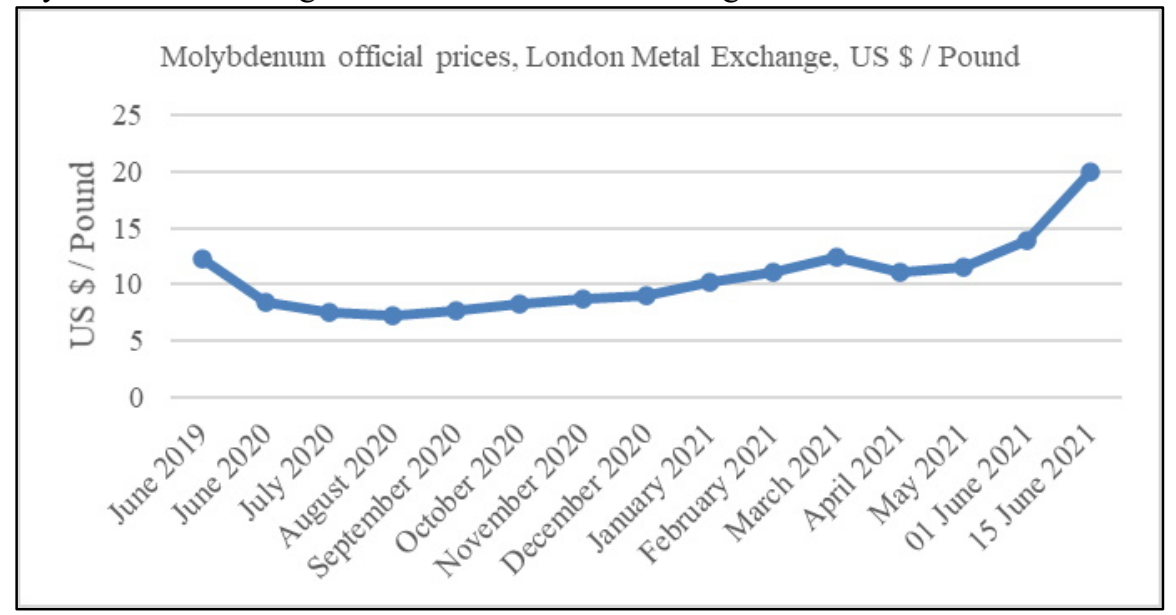

Fig. 3. Prices of molybdenum based on the London Metal Exchange for the period 2017-2021

Cobalt is a critical raw material which is also essential for the raw mineral resources industry. It is a significant factor for technological capabilities and the development of a lowcarbon future, too.

The EU Roadmap for the Circular Economy [12] emphasizes the reuse and the 
Resource recovery as a key strategy to mitigate possible supply disruptions and to ensure resource efficiency and cyclical use.

This is illustrated by the recycling of EoL (End-of-Life) battery materials, which play a key role in providing sufficient cobalt salts for production of lithium cobalt oxides for the batteries needed for hybrid and electric vehicles (EVs). [13]

The EU Commission promotes various industrial initiatives focused on developing the value chain for the battery sector in the EU through the policy framework of the European Battery Alliance [14]. Cobalt compounds are key raw materials in the production of catalysts, which are used worldwide for the production of clean fuels for transport. Cobalt has a key role in achieving the EU's sustainable goals and implementing the climate change / clean air initiatives. In this context and given the significance of the material, the high prices of cobalt based on the prices of the London Metal Exchange are completely logical. (Fig. 4).

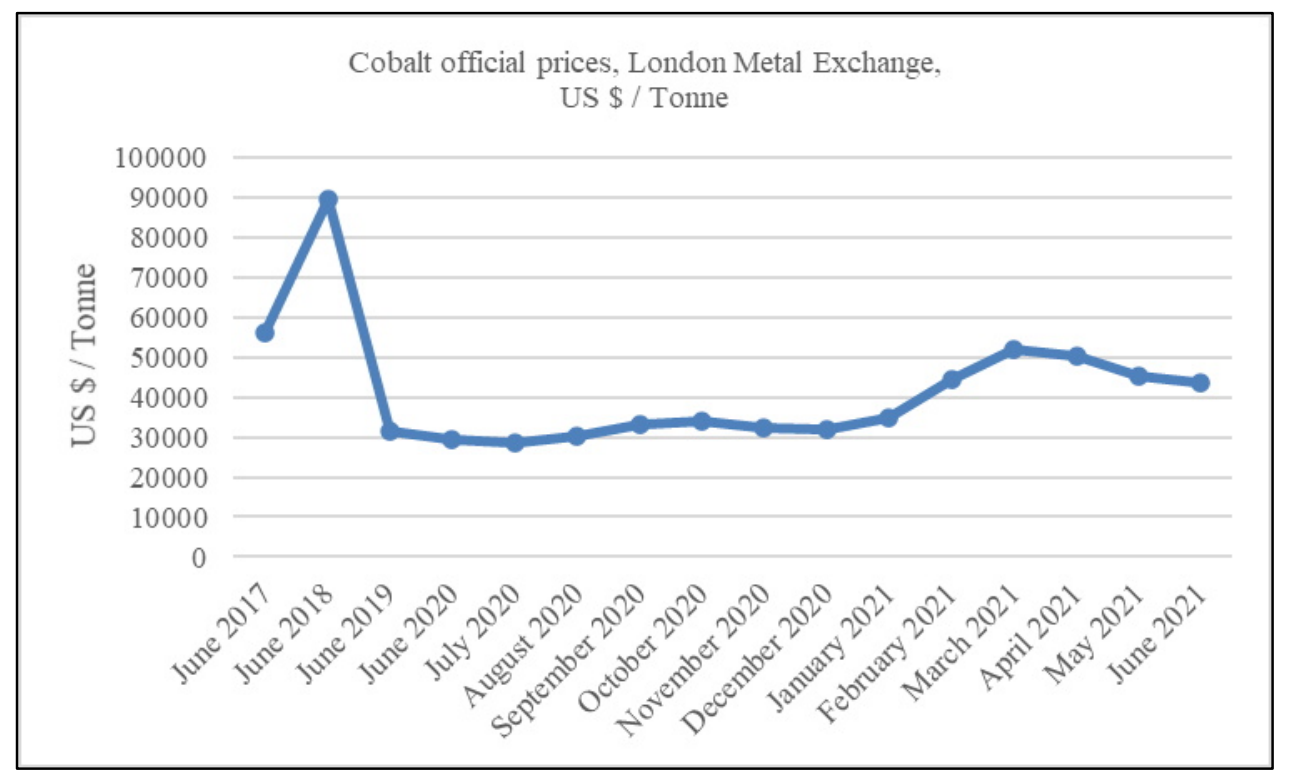

Fig. 4. Prices of cobalt based on the London Metal exchange for the period 2017-2021

The recycling of metals, such as nickel, creates a favorable perspective for protection of both the environment and the development of industry. The nickel is one of the non-ferrous metals that can be recycled many times without affecting their quality.

Nickel recycling efficiency is one of the highest in the industry. The recycling is an important factor in the nickel life cycle and an important factor in the global sustainability. Products containing nickel, such as stainless steel, are durable and are intended for a longterm use. The demand for recycled nickel is growing and it is a part of the solution in addition to the primary production.

Although this publication reviews recycling as an environmental activity, it actually covers a lucrative economic sector that has been existing for thousands of years. In many countries, collection, sorting, preparation, transportation and use of scrap provides a livelihood for more people than ore mining. [15]

Nickel and nickel-containing alloys can be restored to their original state or converted into a different but yet that valuable product. Examples for such are nickel-containing stainless steel products converted to new stainless steel or nickel from recycled batteries used for nickel-containing stainless steel. Based on the London Metal Exchange, the prices per ton of nickel are fully justified and tracking them in retrospect marks the maintenance of stable price levels. (Fig. 5) 


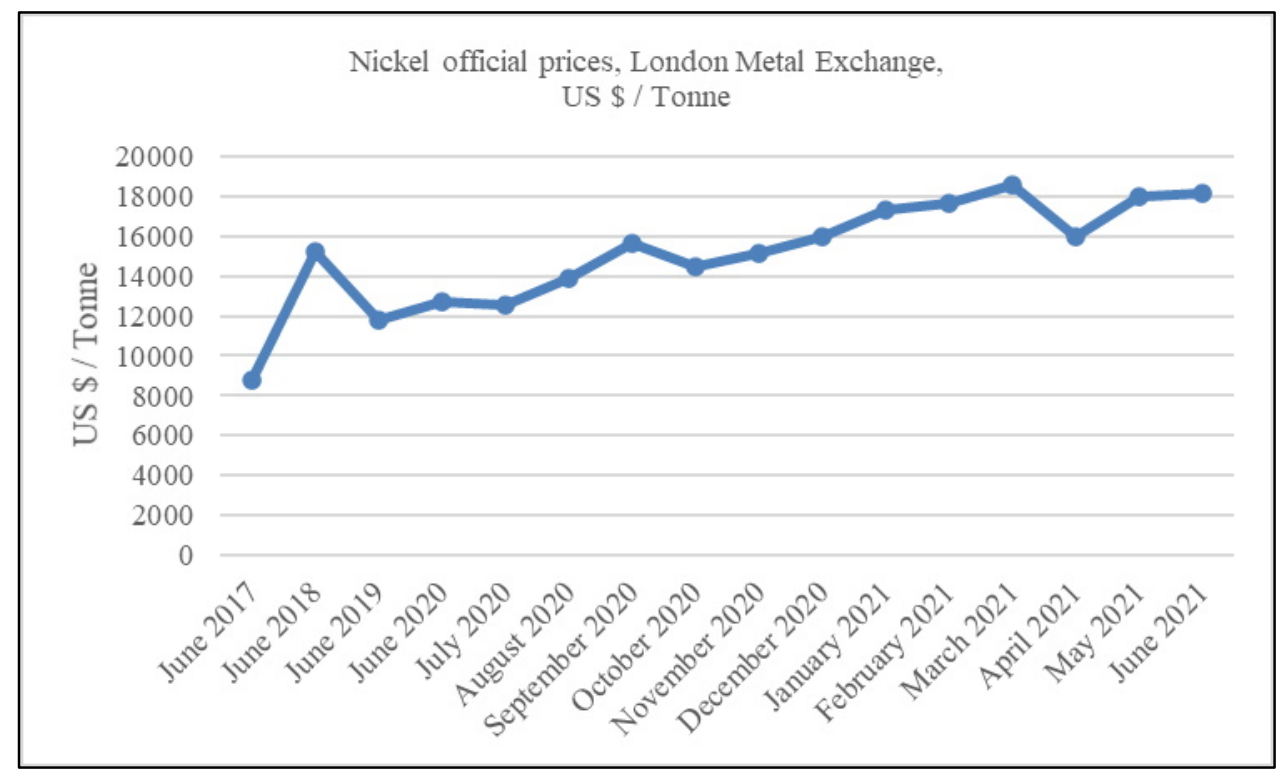

Fig. 5. Prices of nickel based on the London Metal Exchange for the period 2017-2021.

A life cycle approach that takes into account material flows at the end of the product's life is preferable. It allows making the most accurate assessment of the environmental and economic consequences aimed at increasing of the recycling. Such an approach provides the decision-makers with the possibility to identify inefficiencies and related environmental impacts, as well as to optimize product recovery and material recycling.

In 2020, an author's survey conducted among 13 leading companies in the raw mineral resources industry shows that the sector has long been working to implement circular processes in its work.

The analysis of the results shows that in most of the surveyed companies circular models for modernization and innovation are applied, namely:

- Possibility for efficient processing of poor ores;

- Closed cycle for industrial water supply;

- Mounting of an installation for extraction and electro winning of cathode copper from mine water, through which an additional by-product is obtained - pure copper;

- Technology for extraction of accompanying gold in copper concentrate, so that precious components are not lost in the waste;

- Applying of a method for backfilling, i.e. the ground sterile rock mass is returned to the underground mine in the form of a pasty filling, is an example of a circular economy. This model that not only reduces the amount of waste deposited on the surface, but is also used the waste as a raw material, which is mixed with cement and returned to the seized chambers, ensuring the stability of the rock massif;

- Use of part of the mine ballast for filling the used spaces underground, for paving during the construction of the underground roads after crushing and for upgrading the walls of the tailings pond;

- In the extraction of limestone, necessary for the production of lime, many additional fractions of material are released, which are not discarded, but sifted and offer on the market for aggregates;

- Use of earth masses and sludge for reclamation of disturbed terrains;

- Delivery to specialized companies of used oils for recycling and use in other industries;

- Recycling of metals used for drilling tool crowns. [16] 


\section{Conclusion}

According to a report published by the World Bank, aluminum, cobalt, copper, iron ore, lead, lithium, nickel and zinc will be needed in much larger quantities to meet global renewable energy targets. By 2050, the world's wind turbines will require 300\% more metals than they do today, solar panels will require $200 \%$ more, and energy storage will require $1000 \%$ more.

It is a fact that the technologies needed for clean energy change - wind, solar, hydrogen and electricity systems - are actually significantly more intensive in their composition than current traditional fossil fuel-based energy supply systems.

According to the OECD Global Forecast, the green transition is expected to increase the global demand for non-ferrous metals faster than any other raw material demand - from 7 to 19 gigatons per year by 2060 . [15]

Electric vehicles, which are crucial to achieving the EU's emissions reduction targets, will also need a lot of new materials that are otherwise not needed for conventional cars. According to a study commissioned by the International Copper Association, more than 100,000 tons of copper will be needed to build the 40 million charging points needed to service the electric vehicles entering the market by 2027. Copper is used in portal charging cables, chargers and wiring to electrical panels. [14]

Aluminum is also recognized for its potential in the transport of renewables because it is such a lightweight material. A car made of aluminum will use less fuel than one made of other materials.

One of the most interesting aspects of aluminum is that it actually compensates its initial energy consumption by providing significant energy savings during the use and recycling phases.

The publication proves the importance of metals in the realization of the concept of circular economy. Moreover, the author's research shows that the topic is not new for the companies from the mineral industry in Bulgaria. The business has long been actively implementing the principles of circular processes in its business model.

\section{References}

1. Euractive, Special Report Metals in the circular economy, 12-16 (2018)

2. M.L.C.M. Henckens, P.P.J. Driessen, E. Worrell, Resour. Conserv.Recycl., 134, 61-69 (2018)

3. EC, First circular economy action plan,https://ec.europa.eu/environment/topics/circulareconomy/first-circular-economy-action-plan_en

4. L. Kyounga, Cha Jongmun, Sustainability, 13(1), 17 (2021)

5. Minerals for Climate Action: The Mineral Intensity of the Clean Energy Transition, WorldBank report, (2020)

6. R. Kleijn, E. van der Voet, G. J. Kramer, L. van Oers, C. van der Giesen, Energy, Elsevier, 36(9), 5640-5648 (2011)

7. U.S. Energy Requirements for Aluminum Production. Historical Perspective, Theoretical Limits and Current Practices, (2007)

8. R. Kleijn, E. van der Voet, G. J. Kramer, L. van Oers, C. van der Giesen, Energy, Elsevier, 36(9), 5640-5648 (2011)

9. International Molybdenum Association (IMOA), A sustainable world with molybdenum, First edition, London, UK, (2015)

10. EC, First circular economy action plan,https://ec.europa.eu/environment/topics/circulareconomy/first-circular-economy-action-plan_en 
11. Cobalt Institute, The world cobalt. The Technology Enabling Material, (2019), https://www.cobaltinstitute.org/assets/files/Pages\%20PDFs/Infographic-Cobalt-TheTechnology-Enabling-Material.pdf

12. EIT InnoEnergy, Building a European battery industry, [Online], https://www.eba250.com/?cn-reloaded $=1$

13. Nickel Institute, The story of nickel, [Online], www.nickelinstitute.org

14. Website of Copper Alliance, https://copperalliance.org/

15. Website of OECD, https://www.oecd.org/

16. V. Petrova, SEPRM J., 1(October), 79-84 2020 